\title{
A Genetic Model of Chronic Rhinosinusitis-Associated Olfactory Inflammation Reveals Reversible Functional Impairment and Dramatic Neuroepithelial Reorganization
}

\author{
Andrew P. Lane, ${ }^{1}$ Justin Turner, ${ }^{1}$ Lindsey May, ${ }^{1}$ and Randall Reed ${ }^{1,2,3}$ \\ ${ }^{1}$ Department of Otolaryngology-Head and Neck Surgery, ${ }^{2}$ Center for Sensory Biology, and ${ }^{3}$ Department of Molecular Biology and Genetics, The Johns \\ Hopkins University School of Medicine, Baltimore, Maryland 21287
}

\begin{abstract}
Inflammatory sinus and nasal disease is a common cause of human olfactory loss. To explore the mechanisms underlying rhinosinusitisassociated olfactory loss, we have generated a transgenic mouse model of olfactory inflammation, in which tumor necrosis factor $\alpha$ (TNF- $\alpha$ ) expression is induced in a temporally controlled manner specifically within the olfactory epithelium (OE). Like the human disease, TNF- $\alpha$ expression leads to a progressive infiltration of inflammatory cells into the $0 \mathrm{E}$. Using this model, we have defined specific phases of the pathologic process. An initial loss of sensation without significant disruption is observed, followed by a striking reorganization of the sensory neuroepithelium. An inflamed and disrupted state is sustained chronically by continued induction of cytokine expression. After prolonged maintenance in a deficient state, there is a dramatic recovery of function and a normal histologic appearance when TNF- $\alpha$ expression is extinguished. Although obstruction of airflow is also a contributing factor in human rhinosinusitis, this in vivo model demonstrates for the first time that direct effects of inflammation on $\mathrm{OE}$ structure and function are important mechanisms of olfactory dysfunction. These features mimic essential aspects of chronic rhinosinusitis-associated olfactory loss, and illuminate underlying cellular and molecular aspects of the disease. This manipulable model also serves as a platform for developing novel therapeutic interventions.
\end{abstract}

\section{Introduction}

Situated at the interface between the organism and the environment, peripheral sensory organs must maintain defensive barriers to protect from external injury and support immune surveillance. Prolonged inflammatory responses in nasal airways occurring in the context of rhinosinusitis may encompass olfactory epithelium $(\mathrm{OE})$ regions and result in permanent sensory deficits (Kern, 2000). Although the OE displays remarkable plasticity and capacity to recover after injury (Leung et al., 2007), chronic inflammation significantly compromises olfactory function. Loss of the sense of smell is a debilitating condition posing significant health risks and sinonasal inflammation is the most frequent etiology of human olfactory dysfunction (Loury, 1990). The mechanisms of olfactory loss in chronic rhinosinusitis are poorly understood. While airflow obstruction contributes to sensory deficits in some cases, functional alterations or neuroepithelial destruction likely also play major roles (Aiba and Nakai, 1991; Doty and Mishra, 2001; Pfaar et al., 2006). Cellular and molecular characterization of inflammatory effects on olfaction are hampered by human

\footnotetext{
Received Sept. 11, 2009; revised Dec. 18, 2009; accepted Dec. 22, 2009.

This work was funded by National Institute of Deafness and Other Communication Disorders, National Institutes of Health Grant R01 DC009026 (A.P.L.).

Correspondence should be addressed to Dr. Andrew P. Lane, Director, Division of Rhinology and Sinus Surgery, Department of Otolaryngology-Head and Neck Surgery, Johns Hopkins University School of Medicine, Johns Hopkins Outpatient Center, 6th Floor, 601 North Caroline Street, Baltimore, MD 21287-0910. E-mail: alane3@jhmi.edu. DOI:10.1523/JNEUROSCI.4507-09.2010

Copyright $\odot 2010$ the authors $\quad 0270-6474 / 10 / 302324-06 \$ 15.00 / 0$
}

olfactory cleft accessibility and limited acute control of inflammatory states.

In the CNS, cytokines regulate apoptosis and cell proliferation, synaptic plasticity, neural transmission, and $\mathrm{Ca}^{2+}$ signaling. Sensory neuronal responses to inflammatory cytokines are largely unexplored except for their possible modulatory role in pain sensation (Uçeyler et al., 2009). Olfactory receptor neurons (ORNs) and their progenitors reside within the nasal mucosa and are thus particularly susceptible to local immune mediators in the setting of rhinosinusitis. We hypothesize that direct and indirect effects of cytokines present within inflamed olfactory neuroepithelium might be responsible for clinical sinusitis-associated olfactory loss.

Among the cytokines present in sinonasal inflammatory diseases, TNF- $\alpha$ is a potent and particularly relevant inflammatory cytokine associated with infection or injury in many cell-types (Feldmann and Maini, 1999; Kollias et al., 1999; Sandborn and Hanauer, 1999). TNF- $\alpha$ can also regulate cell proliferation, differentiation, and apoptosis in noninflammatory contexts (Zúñiga-Pflücker et al., 1995; Arnett et al., 2001; Barker et al., 2001; Li and Schwartz, 2001). These opposing effects are mediated in part by proapoptotic caspase cascades or proinflammatory NF- $\kappa$ B-mediated states (Scherbel et al., 1999). The role of TNF- $\alpha$ in human olfactory physiology is unknown, but it induces apoptosis of mature ORNs in OE explants (Suzuki and Farbman, 2000).

We have developed a mouse model that mimics clinical aspects of human rhinosinusitis-associated olfactory loss, to ex- 
plore inflammation-associated olfactory loss in vivo. By directing reverse tetracycline transactivator (rtTA) expression using the olfactory sustentacular cell-specific promoter cyp2g1, we have generated tissue-specific, temporally controlled cytokine production in the OE. The consequences of olfactory TNF- $\alpha$ induced inflammation have been investigated in this mouse model, allowing us to address fundamental questions regarding the relationship between chronic rhinosinusitis and olfactory dysfunction.

\section{Materials and Methods}

Generation of the IOI mouse. The IOI (inducible olfactory inflammation) mouse line was created by introduction of the Tet-on genetic system (Clontech) under the control of the olfactory-specific cyp2g1 promoter. A 3581 bp 5'-flanking fragment of the mouse Cyp2g1 gene was isolated from a 129SV BAC (RP22-298K23, Invitrogen) following digestion with PstI and BamHI, and subcloned into pBS. A $1.0 \mathrm{~kb}$ EcoRI-BamHI fragment encoding rtTA from the plasmid pTetOn (Clontech) was cloned and modified to include a 32 bp upstream fragment between the $5^{\prime}$ cyp2g1 BamHI site and the cyp2g1 transcription start site. A $1388 \mathrm{bp}$ EcoRI fragment and adjacent 5154 bp EcoRI fragment were cloned to yield a 3' fragment encompassing the first $6542 \mathrm{bp}$ of the cyp $2 \mathrm{~g} 1$ coding region. A floxed neomycin resistance cassette (Zhao and Reed, 2001) was inserted between rtTA and the downstream arm. All cloning junctions were confirmed by nucleotide sequencing. The Cyp2g1-rtTA construct (Fig. 1a) was released from the vector by digestion with XhoI and KpnI and electroporated into 129SV mouse embryonic stem cells. Homologous recombination events were identified, the positive clones were injected into BL6 blastocysts to generate chimeric mice, and germline transmission was established.

Genetically modified mice with the murine TNF- $\alpha$ gene under control of the tetracycline-responsive element (TRE) were generously provided by Dr. Gary Hoyle (University of Louisville, Louisville, KY) (Vuillemenot et al., 2004), and housed under specific pathogen-free conditions. These mice, generated initially on a BL6/SJL background, were maintained by sibling crosses with BL6/129SV background mice. The IOI mouse line (Cyp2g1-rtTA; TRE TNF-a), was genotyped by PCR to identify appropriate mice for subsequent experiments. The IOI line was maintained by sibling crosses. TNF- $\alpha$ expression levels in the transgenic line were variable (Vuillemenot et al., 2004) and confirmed in DOX-induced animals used for EOG recordings using ELISA of nasal lavage fluid (see below).

Analysis of transgene expression. TNF- $\alpha$ expression was determined by RT-PCR of RNA isolated from the olfactory mucosa after doxycycline (DOX) induction, and by ELISA on nasal lavage fluid collected by perfusing $250 \mu \mathrm{l}$ of PBS over the bisected nasal cavity. The fluid was stored at $-80^{\circ} \mathrm{C}$ for subsequent analysis. TNF- $\alpha$ was quantified using ELISA according to the manufacturer's instructions (R\&D Systems).

In addition, Cyp2g1-rtTA expression was assessed in a mouse line generously provided by Dr. Rolf Sprengel (Max Planck Institute, Heidelberg, Germany) that contains TRE driving both GFP and LacZ reporters (Krestel et al., 2001). The cyp2g1-rtTA and TRE-LacZ/GFP lines were crossed and DOX-dependent induction of LacZ and GFP expression examined by whole-mount X-gal staining (Mombaerts et al., 1996) and by fluorescence microscopy on fixed cryosections.

Histologic analyses. Mouse nasal cavities were embedded in paraffin or were processed for frozen sections. After being killed by $\mathrm{CO}_{2}$ inhalation, mice were decapitated and the heads were fixed and decalcified by immersion in TBD2 solution (Shandon) for $24 \mathrm{~h}$. The heads were then embedded in paraffin, and $12 \mu \mathrm{m}$ sections were obtained and collected on glass slides for hematoxylin and eosin staining. For frozen section analysis, mice were anesthetized by intraperitoneal injection of 100 $\mathrm{mg} / \mathrm{kg}$ xylaket (Sigma), before intracardiac perfusion with $4 \%$ paraformaldehyde. The olfactory tissue was then dissected, postfixed in $4 \%$ paraformaldehyde, and transferred to a solution of 30\% sucrose and $250 \mathrm{~mm}$ EDTA for $48 \mathrm{~h}$. The decalcified heads were then infiltrated with OCT Tissue-Tek compound (Miles) and frozen on dry ice into a plastic mold. Sections of mouse olfactory tissue in OCT were cut on a cryostat $(12 \mu \mathrm{M})$, placed on Fisher Superfrost Plus slides, and dried 60 min before use. a

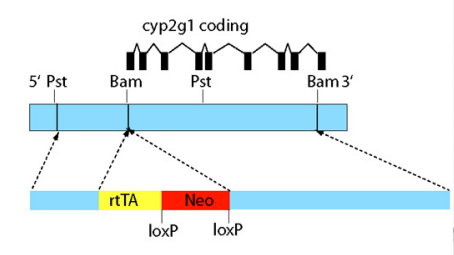

b

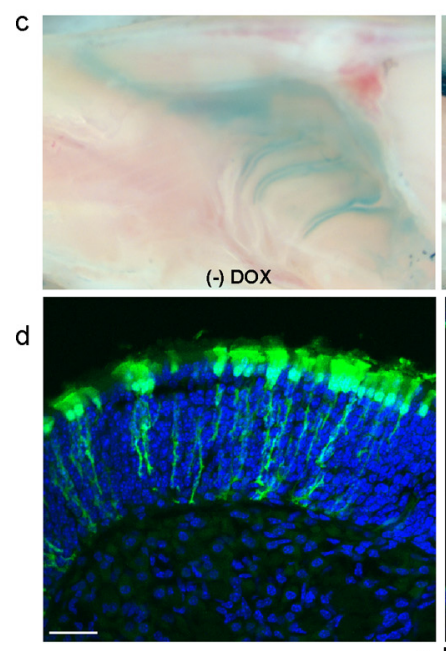

e
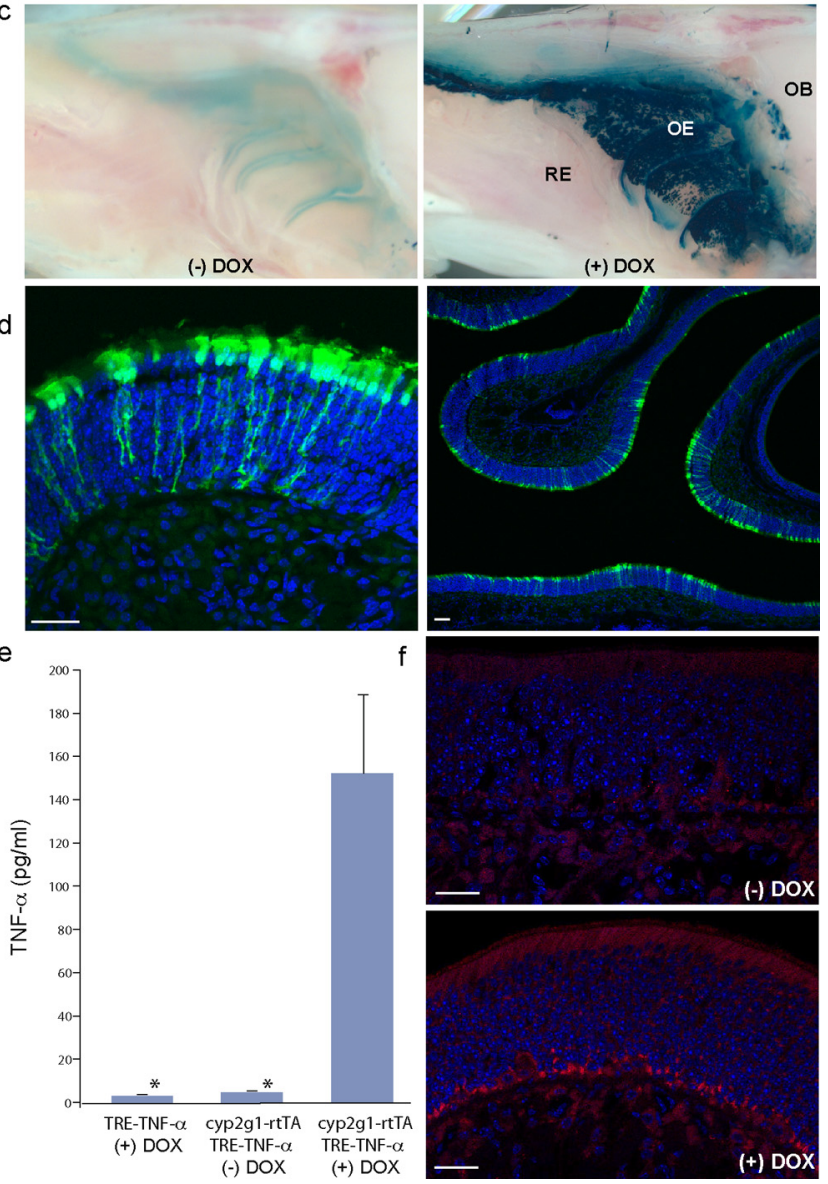

Figure 1. $\quad \boldsymbol{a}$, Schematic of cyp2g1-rtTA genetically modified mice. The rtTA DOX regulated transcriptional activator was inserted at the translation initiation codon for the cyp2g1 gene resulting in the deletion of 8 exons. $\boldsymbol{b}$, In situ hybridization with the cyp2g1 coding region on olfactory cryosections reveals restricted expression in sustentacular cells and the ducts of Bowman's glands. c, The cyp2g1rtTA mice were crossed to a TRE-lacZ/GFP tandem reporter and whole-mount X-gal stains of the nasal cavity prepared. In the absence ofDOX (left), no staining is observed in the tissue. After feeding DOX for $7 \mathrm{~d}$ (right), specific, intense staining is observed across the sensory epithelium. RE, Respiratory epithelium; $\mathrm{OE}$, olfactory epithelium; $\mathrm{OB}$, olfactory bulb. $\boldsymbol{d}$, The reporter induction was visualized by direct imaging of the intrinsic GFP fluorescence in cryosections. At high magnification (left), GFP (green) is restricted to the soma of the apical-located sustentacular cells and their basal processes. Nuclei are identified by DAPI staining (blue). Low-magnification (right) images reveal the broad but not uniform expression in the sustentacular cells. The scale bar in each panel $=25 \mu \mathrm{m} . \boldsymbol{e}$, Induction of TNF- $\alpha$ in olfactory epithelium. Expression of TNF- $\alpha$ was assessed by lavage of nasal cavity and quantitative ELISA. The expression of TNF- $\alpha$ is dependent on the cyp2g1-rtTAlocus and the DOX inducer (7d). Error bars represent \pm SEM ( $n=2$ mice, TRE-TNF with dox; $n=3$ cyprtTA/TNF no dox, cyprtTA/TNF with dox). Bars indicated with asterisks are at or below the reported sensitivity of the assay. $f$, Immunofluorescence on olfactory epithelium cryosections with anti-TNF- $\alpha$ antibody reveals DOX-inducible expression of TNF- $\alpha$ in the sustentacular cell soma and enrichment in the endings of their basal processes. The scale bar in each panel $=25 \mu \mathrm{m}$.

Immunostaining. Cryostat sections were blocked for $1 \mathrm{~h}$ in PBS containing 4\% normal secondary serum and then incubated overnight at $4^{\circ} \mathrm{C}$ in $2 \%$ normal serum containing primary antibody to either CD-68 (Serotec) or BrdU (AbCam). Primary antibodies were detected 
using fluorescent-tagged secondary antibodies, Alexa488 or Alexa594 (Invitrogen).

Electro-olfactogram. The medial surface of the olfactory turbinates was prepared for recording after the animal was killed using $\mathrm{CO}_{2}$. Odorant solutions (Aldrich) were prepared in DMSO and diluted with water to the working concentration just before EOG recording. Test odorants for air delivery were prepared at liquid concentrations of $10^{-3}$ [final DMSO concentration of $0.2 \%(\mathrm{v} / \mathrm{v})]$, and diluted to $10^{-4}$ and $10^{-5} \mathrm{M}$ concentrations. Responses to DMSO diluent alone were measured. Odorant stimulation was delivered in the vapor phase as a $100 \mathrm{~ms}$ pulse by injection into the continuous stream of humidified air. The odorant stimulus pathway was cleaned by air between each stimulus presentation with a minimum interval of 1 min between two adjacent stimuli.

$B r d U$ labeling. Mice were injected intraperitoneally with BrdU (Sigma; $50 \mu \mathrm{g} / \mathrm{g}$ of body weight) $60 \mathrm{~min}$ before they were killed. PFAfixed sections were incubated with $3 \mathrm{~N} \mathrm{HCl}$ for 30 min before immunostaining with antiBrdU antibody (rat, 1:100; Abcam).

\section{Results}

\section{Tet-regulated expression in mouse} olfactory epithelium

The application of doxycycline-inducible (DOX) tet-regulated activation systems permits spatially and temporally controlled expression of target genes (Kistner et al., 1996). We generated a precise genetic replacement of rtTA for the coding region of cyp2g1 (Fig. 1a), a cytochrome P-450 enzyme selectively and highly expressed in olfactory sustentacular cells (Fig. 1b). Sustentacular cells are retained during sensory neuronal turnover and thus eliminate confounding effects of expression in the odorant-responsive cells (Caggiano et al., 1994). A Cyp2g1-rtTA mouse line was established and crossed to transgenic mice carrying a tet-response element (TRE) construct driving expression of a GFP/LacZ tandem reporter. Induction with DOX resulted in robust LacZ expression that was restricted to the olfactory mucosa and inducer-dependent (Fig. 1c). In cryosections, GFP was restricted to sustentacular cell bodies along the apical aspect of the $\mathrm{OE}$ and their processes that extend to the basal lamina. The GFP reporter was induced in only a subset of the OE sustentacular cells (Fig. 1d) but there was no evidence of zonal or domain-specific patterns (Ressler et al., 1993). These observations suggest that this system should deliver widespread and experimentally controllable secreted TNF- $\alpha$ to the $\mathrm{OE}$.

The Cyp-rtTA mice were crossed to transgenic mice carrying a SV40 promoter/tet response element (SV40-TRE) driving TNF- $\alpha$ (Vuillemenot et al., 2004). In nasal lavage of Cyp-rtTA/ TRE-TNF- $\alpha$ mice (inducible olfactory inflammation- IOI mice), TNF- $\alpha$ was below the sensitivity of the ELISA assay (5 $\mathrm{pg} / \mathrm{ml}$ ) in the mice lacking the Cyp2g1 promoter-driven rtTA transcription factor or in IOI mice in the absence of inducer, but TNF was present at $152 \mathrm{pg} / \mathrm{ml}$ after $7 \mathrm{~d}$ of DOX induction. This level represents a minimum of a 20 -fold increase after DOX treat- ment (Fig. 1e), although the actual induction ratios could be much larger. Anti-TNF- $\alpha$ antibody staining revealed specific signal in the apical cytoplasm and basal foot-processes of sustentacular cells (Fig. $1 f$ ). We observe no olfactory pathology in IOI mice in the absence of DOX, or when mice carrying only the TRETNF- $\alpha$ construct are treated with DOX, even for prolonged periods.

\section{Induction, maintenance, and reversal of TNF- $\alpha$ expression} In DOX-fed IOI animals, the architecture of the olfactory epithelium during the first $14-21 \mathrm{~d}$ was essentially normal (Fig. $2 a$, top). The ORN layer thickness shows substantial reduction beginning at $28 \mathrm{~d}$ and is markedly abnormal at 35 and $42 \mathrm{~d}$. Interestingly, while the neuronal cells within the OE were largely depleted, sustentacular cells appeared unaffected, despite the fact that they were the source of the TNF- $\alpha$ (Fig. $2 a$ ). The subepithelium undergoes a reciprocal change upon DOX administration. It is initially normal with some animals displaying a modest increase in thickness by $14 \mathrm{~d}$. The axon bundles appear somewhat smaller, but their highly variable size and number in different regions of the olfactory cavity made these changes difficult to characterize and quantify. A progressive widening of the subepi- 

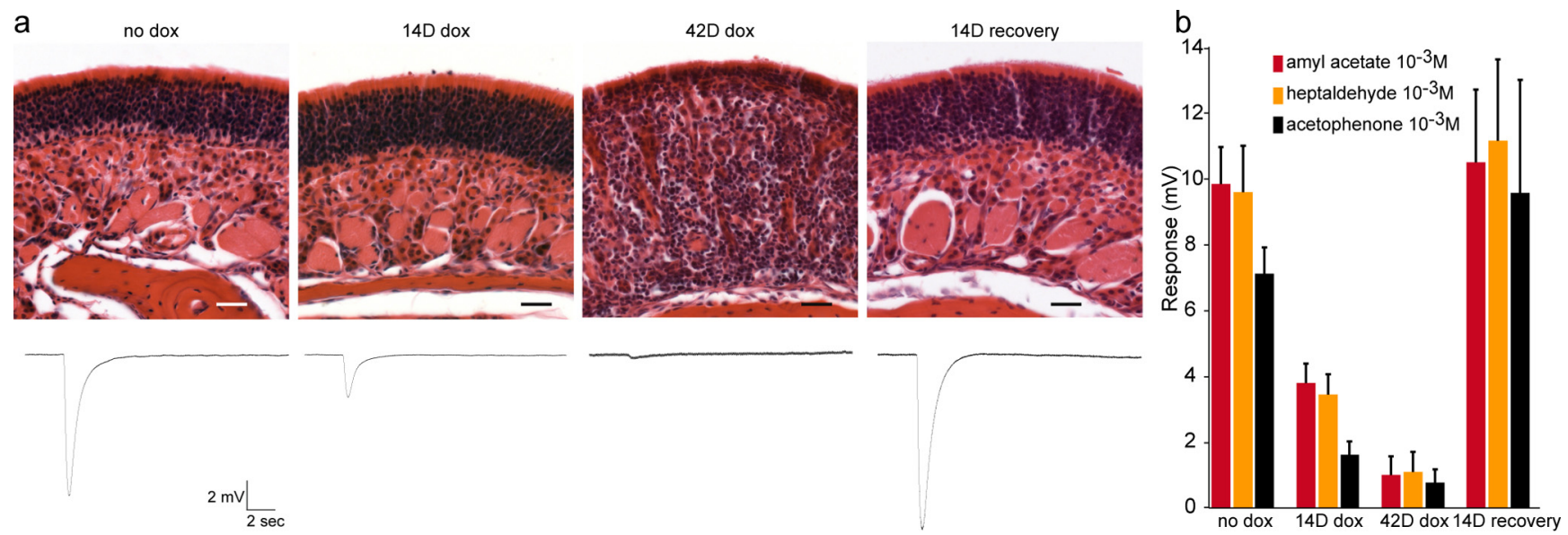

Figure 3. Functional loss and recovery in the $\mathrm{IOI}$ mouse. $\boldsymbol{a}$, EOG recordings after exposure to vapor phase of $10^{-3} \mathrm{~m}$ amyl acetate and corresponding tissue histology. The responses after $14 \mathrm{~d}$ of DOX exposure are reduced despite retention of nearly normal histology. 0 dor responses are nearly absent at $42 \mathrm{~d}$. The recovery of epithelial architecture is accompanied by an essentially normal EOG. $\boldsymbol{b}$, Quantitative assessment of EOG responses for three odorants and each time point. Data reflect a minimum of 4 independent recordings. Error bars represent SEM.

thelium initiates at approximately day 21 accompanied by considerable inflammatory infiltrate and indistinct axon bundles. After DOX induction for $42 \mathrm{~d}$, numerous macrophages were observed by anti-CD68 immunostaining (data not shown). This chronically inflamed and neuron-depleted state observed at $42 \mathrm{~d}$ is maintained as long as DOX is administered $(>90 \mathrm{~d})$.

To identify the cells lost upon DOX administration, a reporter, OE3/EBF2-tauGFP (Wang et al., 2004), that marks the neuronal lineage in OE was introduced into IOI mice. This reporter confirms the rapid and essentially complete loss of neuronal cells and their corresponding axons at $42 \mathrm{~d}$ (Fig. $2 a$, bottom).

Given the remarkable neuronal regenerative capacity in this sensory system, we next examined whether the extensive damage associated with inflammation was reversible. DOX was withdrawn after $42 \mathrm{~d}$ of continual treatment and the tissue examined at several time points (Fig. 2b). At $8 \mathrm{~d}$ after DOX, significant inflammatory infiltrate remains, but modest OE thickening is observed along with $\mathrm{OE} 3-\mathrm{GFP}^{+}$neuronal cells. By $14 \mathrm{~d}$ after DOX withdrawal, the $\mathrm{OE}$ is extensively regenerated and there is nearly normal axon bundle morphology. At $28 \mathrm{~d}$ (Fig. 2b, right; supplemental Fig. $1 a$, available at www.jneurosci.org as supplemental material) the $\mathrm{OE}$ is indistinguishable from genetically identical animals in the absence of the inducer (Fig. 2a, left; supplemental Fig. $1 a$, available at www.jneurosci.org as supplemental material). These observations suggest that the regenerative capacity of the system is retained even after prolonged TNF- $\alpha$ exposure and provides additional insight into the nature of the initial inflamed state.

\section{Electrophysiologic effects of TNF- $\alpha$ in the OE}

We next examined the consequences of TNF- $\alpha$ on sensory function. The response of the OE to odorants was assessed by electroolfactogram (EOG) recordings. After $14 \mathrm{~d}$ on doxycycline, a time point when the epithelial layer is histologically normal, odorantinduced EOG amplitudes are reduced $\sim 60 \%$ (Fig. $3 a$ ). Microarray analysis (Sammeta et al., 2007) and acutely dissociated recordings suggest that ORNs express TNF- $\alpha$ receptors and respond to TNF- $\alpha$ with intracellular $\mathrm{Ca}^{2+}$ changes (A. P. Lane, unpublished results). We suggest that reduced EOG responses reflect chronic desensitization of the ORNs. After $42 \mathrm{~d}$ on doxycycline, EOG responses, even at the highest odorant concentrations, were essentially absent, consistent with the elimination of
ORNs from the OE. The EOG amplitudes returned to normal when DOX was discontinued for $14 \mathrm{~d}$ and the OE allowed to regenerate (Fig. 3b). These functional studies indicate two distinct phases of the inflammation-induced olfactory deficit: an initial phase of physiological desensitization is followed by a cellular loss that results in profound elimination of sensory activity. Importantly, if inflammation resolves and neuronal repopulation occurs, odorant responses are restored to apparently normal efficacy.

\section{TNF- $\alpha$ exposure alters proliferation}

The chronically neuron-depleted state observed upon continual inflammation could arise from a failure of new ORNs to mature and survive within the OE. Alternatively, inflammation could block the proliferation of basally located progenitors and restrict the repopulation by new ORNs. The adult mouse OE contains few BrdU-positive dividing cells, but rapidly transitions to a proliferative mode in models of neuronal depletion (Leung et al., 2007). In the IOI mouse treated with DOX, there was no increase in $\mathrm{BrdU}^{+}$cells, even as the ORNs were depleted (Fig. 4). Within $3 \mathrm{~d}$ of discontinuation, a dramatic increase in $\mathrm{BrdU}^{+}$proliferating cells could be observed within the OE. The increase in $\mathrm{BrdU}^{+}$ cells was maintained with labeled cells distributed throughout the OE. After $14 \mathrm{~d}$, the proliferation was largely confined to cells in the basal layer. As expected, GAP43 ${ }^{+}$neuronal progenitors that would normally reside in the basal region of the epithelium disappear during prolonged DOX exposure. Their reappearance (8 $\mathrm{d}$ after DOX) and transient expansion follows the wave of increased proliferation within the epithelium. Even at $28 \mathrm{~d}$ after doxycycline, $\mathrm{BrdU}^{+}$cells were present at elevated levels although the OE approximated its baseline thickness. The apparent early block during the presence of the cytokine in the regenerative process that leads to neuronal replacement reveals an additional mechanism of inflammation-induced olfactory loss.

\section{Discussion}

In this study, we have generated a novel genetic model of olfactory inflammation that provides insight into the mechanisms underlying human olfactory loss associated with chronic rhinosinusitis. Temporally controlled induction of TNF- $\alpha$ by olfactory sustentacular cells results in progressive inflammation of the sensory epithelium, with decreased electrophysiologic odorant re- 


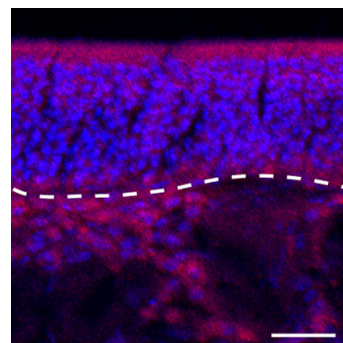

No Dox

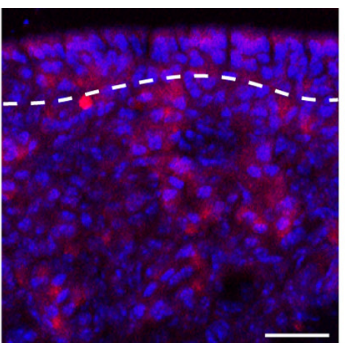

42D Dox

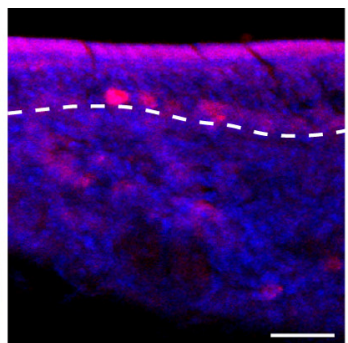

8D Post-Dox

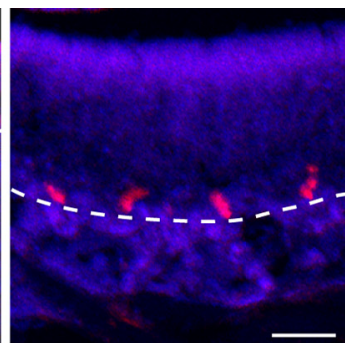

14D Post-Dox

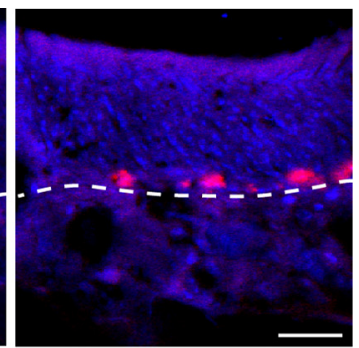

28D Post-Dox

Figure 4. Regenerative state of olfactory epithelium in I0I mice. Proliferating cells are labeled with BrdU and visualized in cryosections. Dividing cells are rare in adult normal olfactory epithelium (left), and the progenitors within the epithelial layer remain quiescent during TNF- $\alpha$ exposure at all time points on DOX. Removal of DOX results in reactivation of proliferation that continues at $28 \mathrm{~d}$. The scale bar in each panel $=25 \mu \mathrm{m}$.

sponses and eventual loss of mature olfactory neurons. The dramatic histopathologic changes were completely reversible once the cytokine induction was discontinued. Our findings suggest that complex olfactory dysfunction associated with inflammation in this mouse model has three distinct origins. First, there is physiologic dysfunction of neurons arising from effects of TNF- $\alpha$ on signaling efficacy. Second, there is a loss of ORNs that results either from direct injury or from damage to the axon bundles required for their survival. Finally, there is a block in the ability of new neurons to be generated in the presence of continued inflammation.

\section{Mechanisms of inflammation-induced olfactory dysfunction}

The initial decrement in olfactory sensitivity observed in the IOI mouse model apparently occurs while the neuronal layer remains histologically normal. Cytokine signaling through $\mathrm{Ca}^{2+}$-mediated pathways is well known as is their role in potentiating or modulating neuronal sensitivity (Zhang et al., 2002). The chronic presence of proinflammatory cytokines could reduce responses by directly opposing odorant-activated signals or more likely by establishing a desensitized state that leads to reduced neuronal firing upon subsequent odor exposure. In EOG recordings, responses reflect the ensemble of neurons expressing odorant receptors types that can recognize that particular ligand. Our studies cannot distinguish between reduced responses in all of the stimulated ORNs versus the complete loss of responsiveness in a fraction of the cells while the remainder of responding neurons in the vicinity of the recording electrode are active. Alternatively, it is possible that the effects of TNF- $\alpha$ exposure are selective for some odorants or receptors, the similar decrement in EOG responses for 3 structurally distinct odorants makes the selective blocking of particular OR subsets by TNF- $\alpha$ unlikely.

One remarkable feature of TNF- $\alpha$ exposure in olfactory tissue is the specificity of its histopathological consequences. The sustentacular cells, basal cells, and submucosal components are retained despite extensive loss of mature neuronal populations. This is especially surprising given the sustentacular cell origin of the secreted TNF- $\alpha$. These cells could be especially resistant to immune surveillance given their role in barrier functions of the epithelium, but the retention of other cells types in the epithelium suggests an alternative mechanism for selective neuronal loss: namely, damage to more distal aspects of the sensory cells. The inflammatory infiltrate that appears in response to local TNF- $\alpha$ expression causes a dramatic expansion of the olfactory submucosa. As the submucosal space becomes tightly packed with inflammatory cells, the axon bundles become irregularly compressed and potentially exposed to macrophage-mediated molecular damage. The intriguing possibility arises that selective olfactory neuron death within the epithelium is a consequence of axonal damage or "squeezing" of axon bundles. Axonal disruption and loss of central connectivity may provide a stimulus for apoptosis, rather than neuronal death due to direct injury to the cell bodies above the basement membrane.

Axonal damage-induced loss of ORNs accounts for the remarkable selectivity of the observed changes and in some respects mimics the axotomy or bulbectomy models for ORN depletion and subsequent replacement (Costanzo and Graziadei, 1983; Verhaagen et al., 1990). In these paradigms in which the injury is acute, the initial stages of regeneration (i.e., proliferation of progenitor populations) is robust and overlaps the removal of the damaged mature cells. The observations in the IOI inflammatory model suggest that a regulated additional block in proliferation is present under conditions of chronic exposure to injury. This controlled delay in proliferation until the inflammatory phase wanes may reduce nonproductive cell division and insure that a more normal epithelial architecture is established.

\section{The IOI mouse and human rhinosinusitis-associated olfactory loss}

In humans, olfactory loss secondary to sinonasal inflammatory disease is a prevalent and debilitating health condition. Limited studies suggest that diminished nasal airflow and destruction of the OE both contribute to the pathophysiology of the CRSassociated olfactory loss. However, the inaccessibility of the olfactory cleft renders detailed investigations of the cellular and molecular basis inherently difficult. Measures of nasal patency correlate imperfectly with the degree of olfactory loss (Lane et al., 1996), and evidence for olfactory mucosal damage are predominantly based on the reduced yield of ORN-containing biopsies from the olfactory region in CRS patients (Lee et al., 2000). Systemic corticosteroids can reverse olfactory loss secondary to CRS, in some cases very rapidly (Ikeda et al., 1995; Stevens, 2001). This observation argues against permanent $\mathrm{OE}$ destruction, and points instead to a critical role for inflammatory cytokines in disease pathogenesis and resolution.

The characteristics of the human disease reconcile well with findings obtained in the IOI mouse model. Specifically, in some circumstances, especially early in the inflammatory process, the rapid reversal of olfactory loss by steroids might occur by suppressing production of cytokines that desensitize resident olfactory sensory neurons. The paucity of neurons present in olfactory biopsies obtained from chronic rhinosinusitis patients may reflect the initial death of these cells and the subsequent repression of regeneration we observe during chronic cytokine exposure. Importantly, the IOI mouse model demonstrates for the first time that a dramatic reorganization of the OE occurs in the set- 
ting of inflammation. A new picture of olfactory loss emerges, wherein progressive submucosal inflammatory infiltration compresses axon bundles and induces olfactory neuron death. The regenerative capacity that ordinarily results in rapid replacement of lost ORNs is remarkably compromised during active inflammation, yet is capable of rapid restoration to reconstitute the neuroepithelium when the inflammatory stimulus is removed. The failure of progenitor cells to replace lost neurons represents a previously unrecognized phenomenon underlying inflammatory olfactory loss that has therapeutic implications. The elucidation and selective intervention in these desensitization and compromised regeneration pathways offers the possibility of targeted topical agents that would improve the sense of smell in the setting of acute and chronic upper respiratory inflammation.

\section{References}

Aiba T, Nakai Y (1991) Influence of experimental rhino-sinusitis on olfactory epithelium. Acta Otolaryngol Suppl 486:184-192.

Arnett HA, Mason J, Marino M, Suzuki K, Matsushima GK, Ting JP (2001) TNF alpha promotes proliferation of oligodendrocyte progenitors and remyelination. Nat Neurosci 4:1116-1122.

Barker V, Middleton G, Davey F, Davies AM (2001) TNFalpha contributes to the death of NGF-dependent neurons during development. Nat Neurosci 4:1194-1198.

Caggiano M, Kauer JS, Hunter DD (1994) Globose basal cells are neuronal progenitors in the olfactory epithelium: a lineage analysis using a replication-incompetent retrovirus. Neuron 13:339-352.

Costanzo RM, Graziadei PP (1983) A quantitative analysis of changes in the olfactory epithelium following bulbectomy in hamster. J Comp Neurol 215:370-381.

Doty RL, Mishra A (2001) Olfaction and its alteration by nasal obstruction, rhinitis, and rhinosinusitis. Laryngoscope 111:409-423.

Feldmann M, Maini RN (1999) The role of cytokines in the pathogenesis of rheumatoid arthritis. Rheumatology (Oxford) 38 [Suppl 2]:3-7.

Ikeda K, Sakurada T, Suzaki Y, Takasaka T (1995) Efficacy of systemic corticosteroid treatment for anosmia with nasal and paranasal sinus disease. Rhinology 33:162-165.

Kern RC (2000) Chronic sinusitis and anosmia: pathologic changes in the olfactory mucosa. Laryngoscope 110:1071-1077.

Kistner A, Gossen M, Zimmermann F, Jerecic J, Ullmer C, Lübbert H, Bujard H (1996) Doxycycline-mediated quantitative and tissue-specific control of gene expression in transgenic mice. Proc Natl Acad Sci USA 93:10933-10938.

Kollias G, Douni E, Kassiotis G, Kontoyiannis D (1999) On the role of tumor necrosis factor and receptors in models of multiorgan failure, rheumatoid arthritis, multiple sclerosis and inflammatory bowel disease. Immunol Rev 169:175-194.

Krestel HE, Mayford M, Seeburg PH, Sprengel R (2001) A GFP-equipped bidirectional expression module well suited for monitoring tetracyclineregulated gene expression in mouse. Nucleic Acids Res 29:E39.

Lane AP, Zweiman B, Lanza DC, Swift D, Doty R, Dhong HJ, Kennedy DW
(1996) Acoustic rhinometry in the study of the acute nasal allergic response. Ann Otol Rhinol Laryngol 105:811-818.

Lee SH, Lim HH, Lee HM, Park HJ, Choi JO (2000) Olfactory mucosal findings in patients with persistent anosmia after endoscopic sinus surgery. Ann Otol Rhinol Laryngol 109:720-725.

Leung CT, Coulombe PA, Reed RR (2007) Contribution of olfactory neural stem cells to tissue maintenance and regeneration. Nat Neurosci 10:720-726.

Li YP, Schwartz RJ (2001) TNF-alpha regulates early differentiation of C2C12 myoblasts in an autocrine fashion. FASEB J 15:1413-1415.

Loury MC (1990) Current concepts in olfaction. Md Med J 39:921-926.

Mombaerts P, Wang F, Dulac C, Chao SK, Nemes A, Mendelsohn M, Edmondson J, Axel R (1996) Visualizing an olfactory sensory map. Cell 87:675-686.

Pfaar O, Landis BN, Frasnelli J, Hüttenbrink KB, Hummel T (2006) Mechanical obstruction of the olfactory cleft reveals differences between orthonasal and retronasal olfactory functions. Chem Senses 31:27-31.

Ressler KJ, Sullivan SL, Buck LB (1993) A zonal organization of odorant receptor gene expression in the olfactory epithelium. Cell 73:597-609.

Sammeta N, Yu TT, Bose SC, McClintock TS (2007) Mouse olfactory sensory neurons express 10,000 genes. J Comp Neurol 502:1138-1156.

Sandborn WJ, Hanauer SB (1999) Antitumor necrosis factor therapy for inflammatory bowel disease: a review of agents, pharmacology, clinical results, and safety. Inflamm Bowel Dis 5:119-133.

Scherbel U, Raghupathi R, Nakamura M, Saatman KE, Trojanowski JQ, Neugebauer E, Marino MW, McIntosh TK (1999) Differential acute and chronic responses of tumor necrosis factor-deficient mice to experimental brain injury. Proc Natl Acad Sci U S A 96:8721-8726.

Stevens MH (2001) Steroid-dependent anosmia. Laryngoscope 111:200-203.

Suzuki Y, Farbman AI (2000) Tumor necrosis factor-alpha-induced apoptosis in olfactory epithelium in vitro: possible roles of caspase 1 (ICE), caspase 2 (ICH-1), and caspase 3 (CPP32). Exp Neurol 165:35-45.

Uçeyler N, Schäfers M, Sommer C (2009) Mode of action of cytokines on nociceptive neurons. Exp Brain Res 196:67-78.

Verhaagen J, Oestreicher AB, Grillo M, Khew-Goodall YS, Gispen WH, Margolis FL (1990) Neuroplasticity in the olfactory system: differential effects of central and peripheral lesions of the primary olfactory pathway on the expression of B-50/GAP43 and the olfactory marker protein. J Neurosci Res 26:31-44.

Vuillemenot BR, Rodriguez JF, Hoyle GW (2004) Lymphoid tissue and emphysema in the lungs of transgenic mice inducibly expressing tumor necrosis factor-alpha. Am J Respir Cell Mol Biol 30:438-448.

Wang SS, Lewcock JW, Feinstein P, Mombaerts P, Reed RR (2004) Genetic disruptions of $\mathrm{O} / \mathrm{E} 2$ and $\mathrm{O} / \mathrm{E} 3$ genes reveal involvement in olfactory receptor neuron projection. Development 131:1377-1388.

Zhang JM, Li H, Liu B, Brull SJ (2002) Acute topical application of tumor necrosis factor alpha evokes protein kinase A-dependent responses in rat sensory neurons. J Neurophysiol 88:1387-1392.

Zhao H, Reed RR (2001) X inactivation of the OCNC1 channel gene reveals a role for activity-dependent competition in the olfactory system. Cell 104:651-660.

Zúñiga-Pflücker JC, Di J, Lenardo MJ (1995) Requirement for TNF-alpha and IL-1 alpha in fetal thymocyte commitment and differentiation. Science 268: 1906-1909. 